\title{
Broadband Carbon-13 Correlation Spectra of Microcrystalline Proteins in Very High Magnetic Fields
}

\author{
Markus Weingarth, ${ }^{\dagger}$ Geoffrey Bodenhausen, ${ }^{\dagger, \ddagger}$ and Piotr Tekely ${ }^{*, \dagger}$ \\ Département de Chimie, Ecole Normale Supérieure, 24 rue Lhomond, 75231 Paris cedex 05, France, and Institut \\ des Sciences et Ingénierie Chimiques, Ecole Polytechnique Fédérale de Lausanne, 1015 Lausanne, Switzerland
}

Received May 4, 2009; E-mail: Piotr.Tekely@ens.fr

Since the first report of a 3D structure of a microcrystalline protein obtained by solid-state NMR, ${ }^{1}$ a variety of strategies have been developed to obtain and analyze two-dimensional (2D) correlation spectra. ${ }^{1-15}$ In uniformly ${ }^{13} \mathrm{C}$ - and ${ }^{15} \mathrm{~N}$-labeled solid proteins, both scalar through-bond and dipolar through-space interactions can be exploited for spectral assignment. Fast magicangle spinning (MAS) of microcrystalline proteins ${ }^{16}$ and peptides ${ }^{17}$ yields 2D homonuclear chemical-shift correlation spectra with good signal-to-noise ratios. ${ }^{16}$ Fast spinning, however, suppresses dipolar interactions between ${ }^{13} \mathrm{C}$ nuclei, which must therefore be reintroduced (or "recoupled") by suitable radio frequency (rf) pulse trains to enable a transfer of magnetization from one ${ }^{13} \mathrm{C}$ to another. However, most recoupling methods were developed at low magnetic fields $\left(B_{0} \leq 12 \mathrm{~T}\right.$, i.e., $v_{0} \leq 500 \mathrm{MHz}$ for $\left.{ }^{1} \mathrm{H}\right)$ and low spinning frequencies $\left(v_{\text {rot }} \leq 10 \mathrm{kHz}\right)$.

This communication presents ${ }^{13} \mathrm{C}-{ }^{13} \mathrm{C}$ correlation spectra of a microcrystalline protein with an unprecedented number of sequential contacts, recorded at $v_{\text {rot }}=23 \mathrm{kHz}$ in a very high magnetic field ( $900 \mathrm{MHz}$ for protons) with the simple pulse sequence shown in Figure 1. The recoupling of the dipolar interactions between ${ }^{13} \mathrm{C}$ nuclei is promoted by our phase-alternated recoupling irradiation scheme (PARIS). ${ }^{18}$ This method uses an rf field applied only to the proton spins $I$ with a moderate constant amplitude $\nu_{1}^{I}$ (see Figure 1 ). The phase is periodically toggled between $+x$ and $-x$ after intervals $\tau_{\mathrm{p}}$ equal to half the rotor period or multiples thereof. In this work, we used $\tau_{\mathrm{p}}=N \tau_{\text {rot }}$ with $N=1 / 2$.

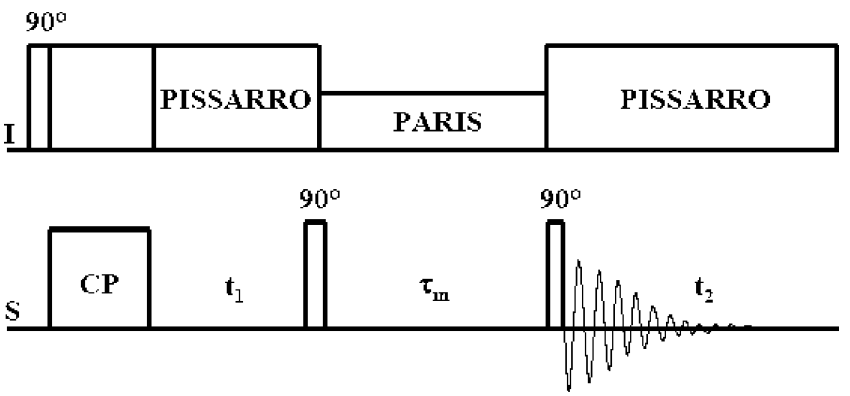

Figure 1. Pulse sequence for $2 \mathrm{D}$ carbon-13 correlation to promote magnetization transfer during the mixing time $\tau_{\mathrm{m}}$ through the phasealternated recoupling irradiation scheme (PARIS). ${ }^{18}$ Heteronuclear PISSARRO $^{19,20}$ decoupling is used during the evolution and acquisition periods. For details of the PARIS and PISSARRO pulse sequences, see the Supporting Information.

In contrast to recoupling schemes based on rotary resonance, ${ }^{21,22}$ the efficiency of PARIS recoupling does not critically depend on the rf amplitude (Figure 4S in the Supporting Information) and is largely immune to the inhomogeneity of the rf field, so the full

\footnotetext{
† Ecole Normale Supérieure.

* Ecole Polytechnique Fédérale de Lausanne.
}

sample volume contributes effectively to the signal. ${ }^{18,23}$ The $\mathrm{rf}$ amplitude need not be matched to the spinning frequency. Even at high spinning speeds (see the Supporting Information), moderate rf amplitudes suffice to bring about efficient magnetization transfer, ${ }^{18}$ thus avoiding excessive sample heating. This opens up new possibilities for efficient dipolar recoupling that are independent of any rotary resonance condition. Since no rf irradiation is applied to the ${ }^{13} \mathrm{C}$ spins, their magnetization remains longitudinal and barely decays during the transfer. Many of these features of PARIS make it an attractive alternative to the popular DARR ${ }^{21}$ recoupling scheme, which does not compensate for rf field inhomogeneity and is not efficient at high spinning frequencies. ${ }^{18}$

Figure 2 shows extracts of a ${ }^{13} \mathrm{C}-{ }^{13} \mathrm{C}$ correlation spectrum of a polycrystalline sample of catabolite repression phosphocarrier protein (Crh) recorded at $21 \mathrm{~T}\left(900 \mathrm{MHz}\right.$ for ${ }^{1} \mathrm{H}, 225 \mathrm{MHz}$ for ${ }^{13} \mathrm{C}$ ) using a $2.5 \mathrm{~mm}$ rotor spinning at $v_{\text {rot }}=23 \mathrm{kHz}$ with PARIS recoupling ${ }^{18}\left(v_{1}{ }^{\mathrm{H}}=23 \mathrm{kHz}\right.$ during $\left.\tau_{\mathrm{m}}=85 \mathrm{~ms}\right)$ and PISSARRO proton decoupling ${ }^{19,20}\left(v_{1}{ }^{\mathrm{H}}=100 \mathrm{kHz}\right.$ during $t_{1}$ and $\left.t_{2}\right)$.

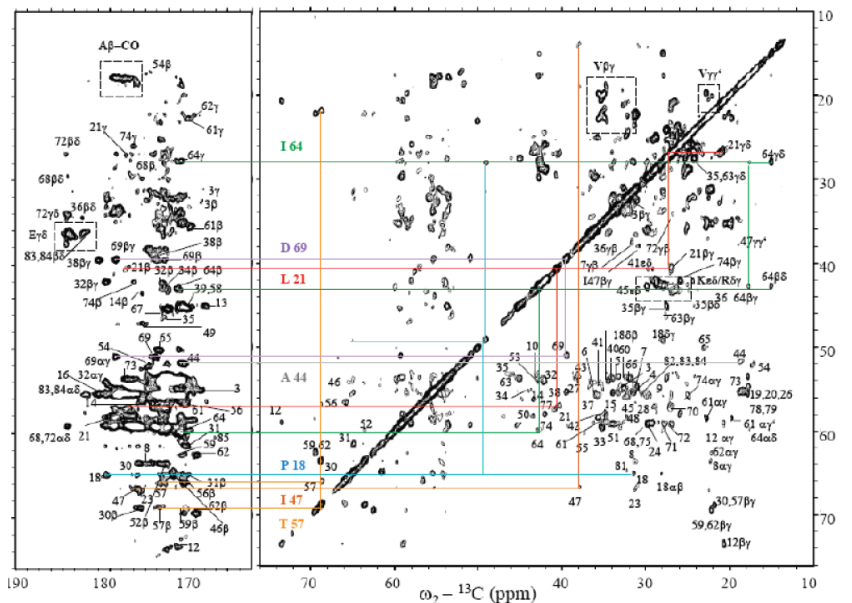

Figure 2. PARIS ${ }^{13} \mathrm{C}-{ }^{13} \mathrm{C}$ correlation spectrum of microcrystalline $\mathrm{Crh}$ recorded in $\sim 13 \mathrm{~h}$ on a $900 \mathrm{MHz}$ spectrometer using a $2.5 \mathrm{~mm}$ rotor, $\tau_{\mathrm{m}}=$ $85 \mathrm{~ms}, v_{1}{ }^{\mathrm{H}}=v_{\text {rot }}=23 \mathrm{kHz}, \tau_{\mathrm{p}}=\tau_{\text {rot }} / 2=21.74 \mu \mathrm{s}$. PISSARRO heteronuclear decoupling ${ }^{19,20}$ with $\nu_{1}{ }^{\mathrm{H}}=100 \mathrm{kHz}$ was used during the evolution and acquisition periods. Some amino acid spin systems are shown in color.

Remarkably, the spectrum of Figure 2 features hardly any uninformative empty areas. Both aliphatic nuclei with closely spaced chemical shifts and spectrally remote nuclei give rise to strong correlations. Although the latter correlations can to some extent be promoted by rotational resonance recoupling under the present experimental conditions, simultaneous magnetization exchange between aliphatic carbons on the one hand and carboxyl and aliphatic carbons on the other could also be promoted at high spinning frequencies contrary to DARR, ${ }^{21}$ by PARIS using longer 
intervals $\tau_{\mathrm{p} .}{ }^{18}$ Indeed, the PARIS scheme can be adapted to any spinning frequency ${ }^{18}$ without losing its broadband properties by using higher multiples of $N$.

The spectrum in Figure 2 reveals intra- and interresidue correlations $^{24,25}$ between amino acids that are closely packed but do not necessarily belong to the same molecule. The $10.4 \mathrm{kDa} \mathrm{Crh}$ protein forms dimers with swapped $\beta$-strands that can be identified through the characteristic shift of the $C^{\alpha} / C^{\beta}$ cross peak of T12 located in the hinge region. ${ }^{26}$ In the single spectrum of Figure 1, 82 out of 85 residues could be identified. The three carbonyl $\mathrm{C}^{\prime}$ resonances of residues L74, E68, and V61 were assigned for the first time.

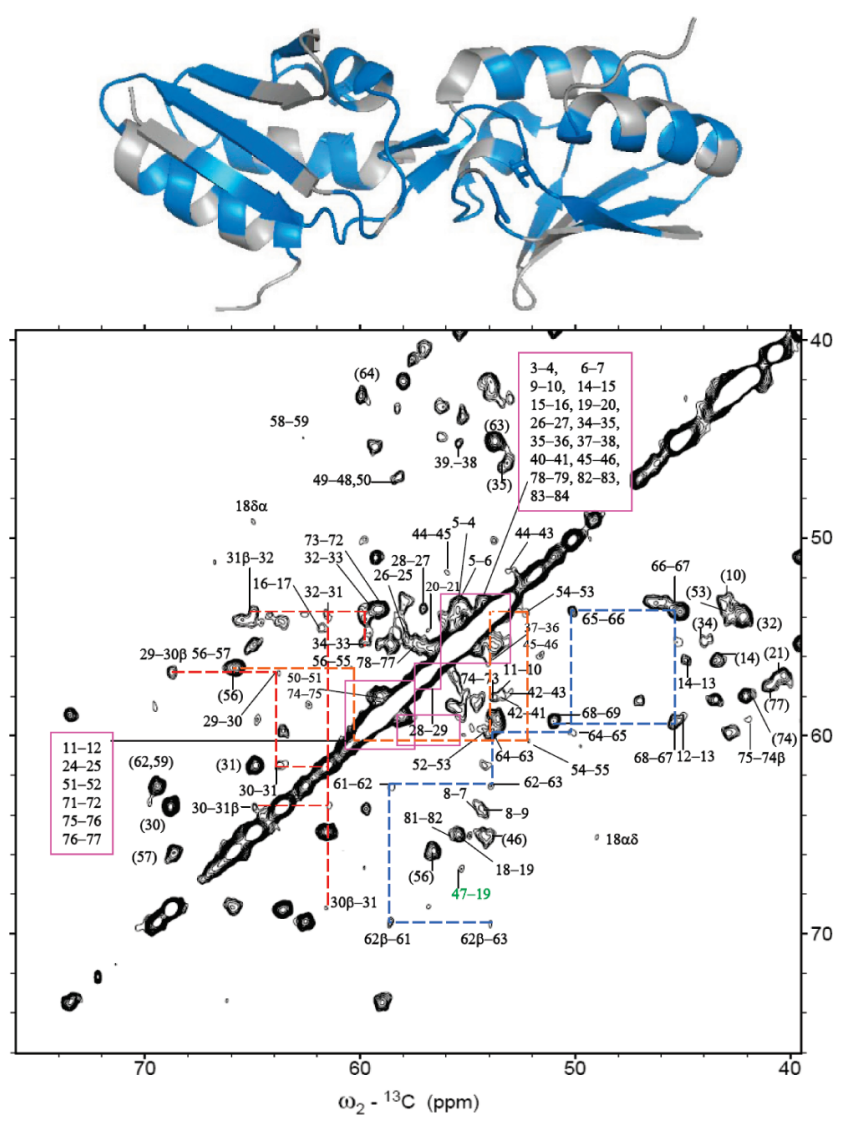

Figure 3. Enlargement of Figure 2 with assignments of some sequential $\mathrm{C}^{\alpha} / \mathrm{C}^{\alpha}$ and $\mathrm{C}^{\alpha} / \mathrm{C}^{\beta}$ cross-peaks stemming from interactions across distances $r$ in the range $3.8<r<4.8 \AA$. A long-range contact $(r=5.7 \AA)$ between I $47 \alpha$ and $\mathrm{A} 19 \alpha$ is highlighted by green numbers (see the Supporting Information). Residues with assigned sequential contacts are shown in blue on the Crh dimer structure representation.

Moreover, 52 sequential $\mathrm{C}^{\alpha} / \mathrm{C}^{\alpha}$ and $\mathrm{C}^{\alpha} / \mathrm{C}^{\beta}$ contacts in addition to eight aliphatic/ $\mathrm{C}^{\prime}$ contacts could be resolved, which, inter alia, allowed us to assign the $\mathrm{C}^{\prime}$ resonance of E68. On the other hand, we were unable to assign $23 \mathrm{C}^{\alpha} / \mathrm{C}^{\alpha}$ cross-peaks that were too close to the diagonal, four peaks that overlapped with intraresidual contacts, nine signals due to mobile residues in loops (T57-V61, V2-Q3, E84-V85), four signals in helix-loop contacts (S46-M48, D69-Q71), and one signal within an $\alpha$-helix (V23-Q24). The nine consecutive residues V61-Q66 from $\beta$-strand 5 and the loop G67-D69 could be clearly assigned through 10 sequential contacts, as shown by the dashed blue lines in Figure 3. Only one of these 10 inter-residual correlations has been observed previously in spectra of Crh obtained with PDSD or DARR recoupling. ${ }^{13,25}$ The set of six consecutive residues 29-34 in $\beta$-strand 2 and its preceding loop give rise to the nine sequential $\mathrm{C}^{\alpha} / \mathrm{C}^{\alpha}$ and $\mathrm{C}^{\alpha} / \mathrm{C}^{\beta}$ contacts highlighted in Figure 3 by dashed red lines. Only five of these contacts were visible with DARR. ${ }^{13}$ Moreover, we observed all of the $C^{\alpha} / C^{\alpha}$ sequential contacts for the five consecutive residues 52-56 in loop L2 (dashed orange lines), of which the DARR spectrum $^{21}$ showed only one. This corroborates our claim ${ }^{18}$ that PARIS recoupling is more efficient than PDSD and DARR (see the Supporting Information.) Thus, we can envisage the use of PARIS recoupling not only in $2 \mathrm{D}$ carbon-carbon correlation experiments but also as a building block in multidimensional NCACB or NCOCX correlation experiments at high spinning frequencies.

Under the present experimental conditions, only a few long-range contacts could be seen in our PARIS spectra. It has been demonstrated that DARR is able to reveal long-range contacts using longer mixing times $\left(\tau_{\mathrm{m}} \approx 200 \mathrm{~ms}\right){ }^{13,27}$ We anticipate that PARIS spectra will have similar properties. Notably, as discussed below, PARIS recoupling also works with modest rf amplitudes, therefore permitting the use of longer mixing times than for DARR.

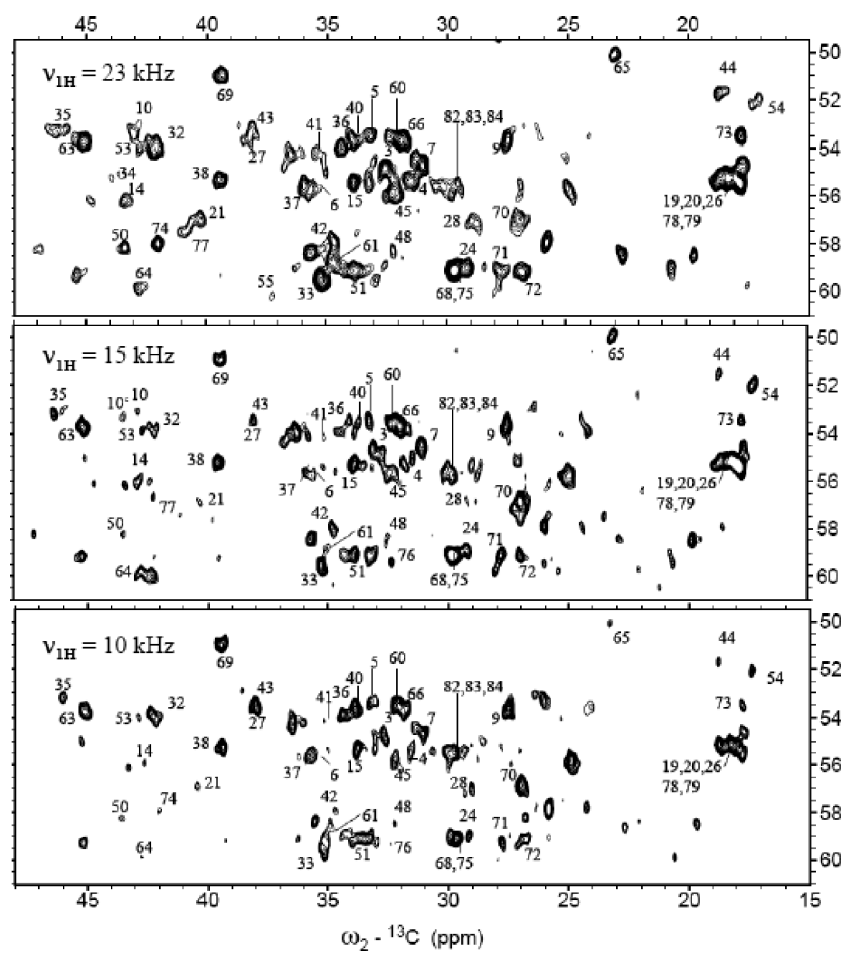

Figure 4. Expansions of ${ }^{13} \mathrm{C}-{ }^{13} \mathrm{C}$ correlation spectra recorded using PARIS recoupling with proton $\mathrm{rf}$ amplitudes and mixing times of (top) $v_{1}{ }^{\mathrm{H}}=23$ $\mathrm{kHz}, \tau_{\mathrm{m}}=85 \mathrm{~ms}$, (middle) $v_{1}^{\mathrm{H}}=15 \mathrm{kHz}, \tau_{\mathrm{m}}=100 \mathrm{~ms}$, and (bottom) $\nu_{1}{ }^{\mathrm{H}}$ $=10 \mathrm{kHz}, \tau_{\mathrm{m}}=150 \mathrm{~ms}$. The $2.5 \mathrm{~mm}$ rotor was spun at $v_{\mathrm{rot}}=23 \mathrm{kHz}$. Each spectrum was recorded in $\sim 13 \mathrm{~h}$.

Very recently, a large number of long-range cross-peaks have been reported in $2 \mathrm{D}$ correlation spectra of $\mathrm{Crh}$ recorded with PAR recoupling. ${ }^{15}$ Although the PAR method seems well-suited for extracting molecular distances, it appears less appropriate for assignment purposes, especially in the presence of a large number of long-range cross-peaks that tend to create uncertainties in spectral assignments. Moreover, to promote broadband magnetization transfer, the PAR method would require excessive rf amplitudes under our experimental conditions.

Enlargements of the aliphatic and carboxyl regions of ${ }^{13} \mathrm{C}-{ }^{13} \mathrm{C}$ PARIS spectra recorded with different $\mathrm{rf}$ amplitudes $\nu_{1}^{\mathrm{H}}$ are shown in Figures 4 and 5. These spectra provide evidence that similar information can be obtained with PARIS recoupling using $v_{1}{ }^{\mathrm{H}}=$ $v_{\text {rot }}$ (i.e., at rotary resonance with $n=1$ ) or with a much lower $\mathrm{rf}$ 
amplitude $v_{1}{ }^{\mathrm{H}} \ll v_{\text {rot }}$, provided that longer mixing times $\tau_{\mathrm{m}}$ are used. This corroborates the fact that PARIS recoupling does not depend critically on the rf amplitude (also see Figure 4S in the Supporting Information) and is able to promote efficient magnetization transfer without fulfilling any rotary resonance condition. ${ }^{18}$

Besides numerous sequential contacts in the range $3.8<r<4.8$ $\AA$, the spectrum of Figure 5 reveals a long-range contact $\mathrm{C}^{\alpha}(\mathrm{G} 58)-\mathrm{C}^{\prime}(\mathrm{V} 8)$ with $r=4.6 \AA$ between residues belonging to the swapped domains (see the Supporting Information). This crosspeak cannot be due to residues located in the same monomeric unit, which are separated by $16.3 \AA$. Another long-range contact between residues I47 and A19 with $r=5.7 \AA$ is highlighted in Figure 3. This confirms that long-range contacts can be detected by using longer mixing periods.

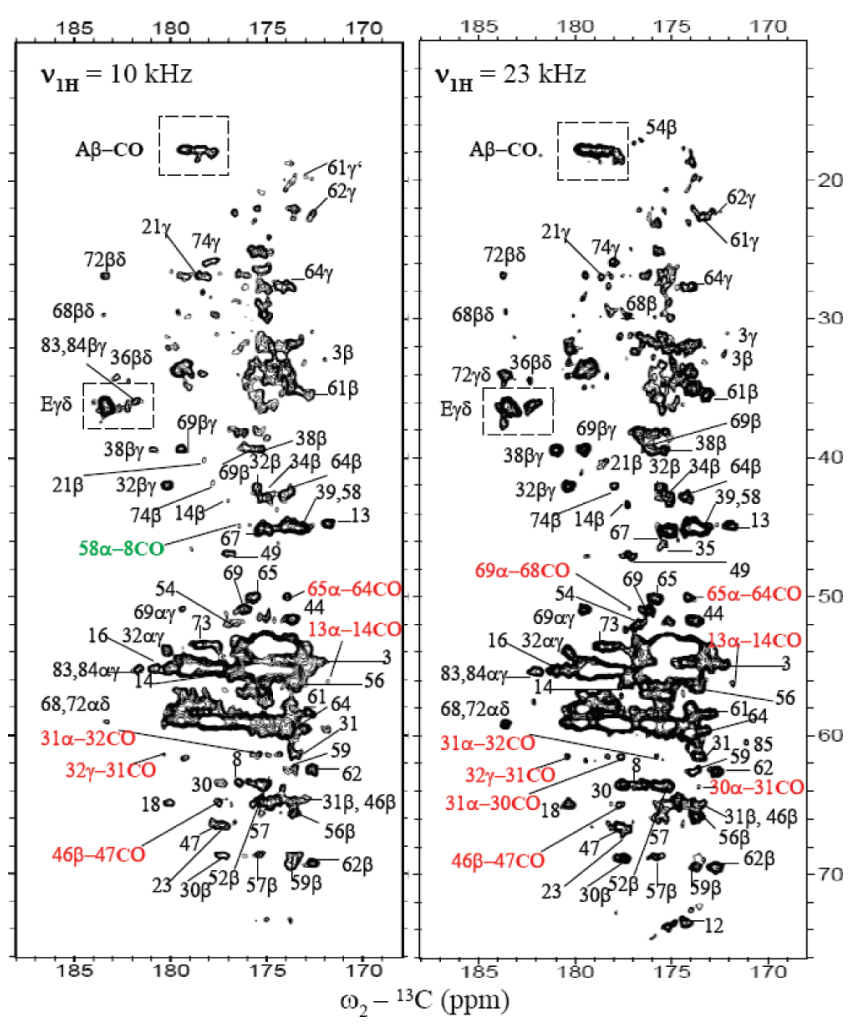

Figure 5. Expansions of ${ }^{13} \mathrm{C}-{ }^{13} \mathrm{C}$ correlation spectra recorded using PARIS recoupling with (left) $v_{1}^{\mathrm{H}}=10 \mathrm{kHz}, \tau_{\mathrm{m}}=150 \mathrm{~ms}$ and (right) $v_{1}^{\mathrm{H}}=23$ $\mathrm{kHz}, \tau_{\mathrm{m}}=85 \mathrm{~ms}$. Sequential contacts with distances $r<4.4 \AA$ are emphasized by red numbers, while a long-range contact $(r=4.6 \AA)$ between residues G58 and V8 in the swapped domain is highlighted by green numbers (also see the Supporting Information).

In summary, we have demonstrated that PARIS recoupling using a low rf amplitude can promote magnetization transfer over a wide range of differences in isotropic chemical shifts in microcrystalline Crh protein at $900 \mathrm{MHz}$. This bodes well for applications to all sorts of biomolecules and materials.
Acknowledgment. Access to the European Center for High Field NMR in Lyon through the Research Infrastructure Activity in the Sixth Framework Program (Contract RII3-026145, EU-NMR) is gratefully acknowledged. Financial support from the TGE RMN THC FR3050 is gratefully acknowledged. We thank A. Böckmann for the generous gift of a Crh sample and many helpful observations and C. Gardiennet for valuable discussions.

Supporting Information Available: Details of the PARIS and PISSARRO pulse sequences, a $1 \mathrm{D}{ }^{13} \mathrm{C}$ spectrum of $\mathrm{Crh}$ protein, longrange contacts in its $3 \mathrm{D}$ structure, simulated magnetization transfer amplitudes for PARIS and DARR, and experimental conditions. This material is available free of charge via the Internet at http://pubs.acs.org.

\section{References}

(1) Castellani, F.; van Rossum, B.; Diehl, A.; Schubert, M.; Rehbein, K.; Oschkinat, H. Nature 2002, 420, 98-102.

(2) Rienstra, C. M.; Tucker-Kellogg, L.; Jaroniec, C. P.; Hohwy, M.; Reif, B.; McMahon, M. T.; Tidor, B.; Lozano-Perz, B.; Griffin, R. G. Proc. Natl. Acad. Sci. U.S.A. 2002, 99, 10260-10265.

(3) Hong, M.; Griffin, R. G. J. Am. Chem. Soc. 1998, 120, 7113-7114.

(4) Astrof, N. S.; Griffin, R. G. J. Magn. Reson. 2002, 158, 157-163.

(5) Lange, A.; Luca, S.; Baldus, M. J. Am. Chem. Soc. 2002, 124, 9704-9705.

(6) Lange, A.; Seidel, K.; Verdier, S.; Luca, S.; Baldus, M. J. Am. Chem. Soc. 2003, 125, 12640-12648.

(7) Igumenova, T. A.; Wand, A. J.; McDermott, A. E. J. Am. Chem. Soc. 2004, $126,5323-5331$

(8) Igumenova, T. A.; McDermott, A. E.; Zilm, K. W.; Martin, R. W.; Paulson, E. K.; Wand, A. J. J. Am. Chem. Soc. 2004, 126, 6720-6727.

(9) Lange, A.; Becker, S.; Seidel, K.; Giller, K.; Pongs, O.; Baldus, M. Angew. Chem., Int. Ed. 2005, 44, 2089-2092.

(10) Zech, S. G.; Wand, A. J.; McDermott, A. E. J. Am. Chem. Soc. 2005, 127, 8618-8626.

(11) Franks, W. T.; Shou, D. H.; Wylie, B. J.; Money, B. G.; Graesser, D. T.; Frericks, H. L.; Sahota, G.; Rienstra, C. M. J. Am. Chem. Soc. 2005, 127, 12291-12305.

(12) Kobayashi, M.; Matsuki, Y.; Yumen, I.; Fujiwara, T.; Akutsu, H. J. Biomol. NMR 2006, 36, 279-293.

(13) Loquet, A.; Bardiaux, B.; Gardiennet, C.; Blanchet, C.; Baldus, M.; Nilges, M.; Malliavin, T.; Böckmann, A. J. Am. Chem. Soc. 2008, 130, 35793589.

(14) Manolikas, T.; Hermann, T.; Meier, B. H. J. Am. Chem. Soc. 2008, 130, 3959-3966.

(15) De Paëpe, G.; Lewandowski, J. R.; Loquet, A.; Böckmann, A.; Griffin, R. G. J. Chem. Phys. 2008, 129, 245101.

(16) Ernst, M.; Detken, A.; Böckmann, A.; Meier, B. H. J. Am. Chem. Soc. 2003, 125, 15807-15810.

(17) De Paëpe, G.; Bayro, M. J.; Lewandowski, J.; Griffin, R. G. J. Am. Chem. Soc. 2006, 128, 1776-1777.

(18) Weingarth, M.; Demco, D. E.; Bodenhausen, G.; Tekely, P. Chem. Phys. Lett. 2009, 469, 342-348.

(19) Weingarth, M.; Tekely, P.; Bodenhausen, G. Chem. Phys. Lett. 2008, 466, 247-251.

(20) Weingarth, M.; Bodenhausen, G.; Tekely, P. J. Magn. Reson. 2009, 199, 238-241.

(21) Takegoshi, K.; Nakamura, S.; Terao, T. Chem. Phys. Lett. 2001, 344, 631637.

(22) Takegoshi, K.; Nakamura, S.; Terao, T. J. Chem. Phys. 2003, 118, 23252541 .

(23) Duma, L.; Abergel, D.; Ferrage, F.; Pelupessy, P.; Tekely, P.; Bodenhausen, G. ChemPhysChem. 2008, 9, 1104-1106.

(24) Böckmann, A.; Lange, A.; Galiniern, A.; Luca, S.; Giraud, N.; Juy, M.; Heise, H.; Montserret, R.; Penin, F.; Baldus, M. J. Biomol. NMR 2003, 27 , 323-339.

(25) Etzkorn, M.; Böckmann, A.; Penin, F.; Riedel, D.; Baldus, M. J. Am. Chem. Soc. 2007, 129, 169-175.

(26) Giraud, N.; Böckmann, A.; Lesage, A.; Penin, F.; Blackledge, M.; Emsley, L. J. Am. Chem. Soc. 2004, 126, 11422-11423.

(27) Marulanda, D.; Tasayco, M. L.; Cataldi, M.; Arriaran, V.; Polenova, T. J. Phys. Chem. B 2005, 109, 18135-18145.

JA9036143 